\title{
A HOT-SPARE INJECTOR FOR THE APS LINAC
}

J.W. Lewellen $^{\dagger}$, K. Thompson, J. Jagger, S.V. Milton, A. Nassiri, M. Borland, D. Advanced Photon Source, Argonne, IL

\begin{abstract}
Last year a second-generation SSRL-type thermionic cathode if gun was installed in the Advanced Photon Source (APS) linac. This gun (referred to as "gun2") has been successfully commissioned and now serves as the main injector for the APS linac, essentially replacing the Koontz-type DC gun. To help ensure injector availability, particularly with the advent of top-up mode operation at the APS, a second thermionic-cathode if gun will be installed in the APS linac to act as a hot-spare beam source. The hot-spare installation includes several unique design features, including a deep-orbit Panofskystyle alpha magnet. Details of the hot-spare beamline design and projected performance are presented, along with some plans for future performance upgrades.
\end{abstract}

\section{INTRODUCTION}

In the coming months the APS linac will be supporting a much broader range of uses than those for which it was originally intended. It will be required to support not only APS user operations with once-per-day fills, but also to support storage-ring top-up mode operation [1] and next-generation light source research such as the APS low-energy undulator test line (LEUTL) project [2].

The LEUTL and other next-generation light source experiments require low-emittance, high-charge single bunches delivered to the end of the linac; and, as this is in support of an experiment and not storage ring operations, injector availability is not as strong of a concern as beam quality. The current injector of choice for LEUTL operations, therefore, is a Brookhaven/SLAC-style photoinjector of gun using a copper cathode and a frequency quadrupled Nd:glass laser to generate the photoelectrons. This injector is due for installation into the APS linac in March ' 99 and will take the place of the DC gun at the head of the linac.

The removal of the DC gun would leave the APS linac with only one high-availability injector, and this has been deemed to be an unacceptable risk to APS operations. Therefore, a hot-spare injector, based on a firstgeneration SSRL-style thermionic cathode gun [3] ("gun1"), has been installed into the APS linac to serve as a backup injector.

This paper details the design requirements of the gun1 injector system, reviews the lattice design used for the gun1 injector, reports on first beam from gun1 into the

* Work supported by the U.S. Dept. of Energy, Office of Basic Energy Sciences, under Contract No. W-31-109-ENG-38.

† email: lewellen @aps.anl.gov
APS linac system, and describes possible upgrades to the primary injection systems of the APS linac.

\section{UPGRADE REQUIREMENTS}

\subsection{Portions of beamline available for injectors}

The APS linac already has an injector located in-line with the first 3-meter SLAC-type structure in the linac line (presently a DC gun, to be replaced by the photocathode gun in March '99). There is a 2.5-meter gap between the first and second linac sections of the APS linac; the gun 2 injector alpha magnet is located approximately 1.4 meters upstream of the entrance to the second linac section in the APS linac [4]. The only reasonable location for a hot-spare injector would be in this same gap between the first and second linac sections, upstream of the gun 2 injector alpha magnet. Other open spaces along the APS linac would either interfere with photocathode gun operation (if located upstream of the first linac section) or would physically not fit into the linac tunnel.

\subsection{Required performance}

Any backup injector for the APS will eventually be required to have the same performance as the standard injector in terms of APS operation: delivered charge to the end of the APS linac, injection efficiency from the linac into the rest of the APS injector system, and availability. It will not be required to serve as a backup or alternate injector for experiments such as LEUTL, and the sole criterion on beam quality is that it be "good enough" to be accepted by the APS linac and downstream injection systems. These criteria should be easily met by a first-generation SSRL-style thermionic cathode rf gun.

\section{BEAMLINE DESIGN AND CONSTRUCTION}

As mentioned above, there are strict constraints on the possible placement of a backup injector in the APS linac line. In addition to fitting an injector into the allowed space, other goals of the design process were to keep the rf gun beamlines as similar as possible, to reduce requirements on spare parts stores, and to reduce training required for maintenance and operation.

The previously installed gun2 beamline is a fairly standard thermionic-cathode rf gun beamline, using an alpha magnet for bunch compression and for injecting

The submitted manuscript has been created by the University of Chicago as Operator of Argonne National Laboratory ("Argonne") under Contract No. W-31-109-ENG-38 with the U.S. Department of Energy. The U.S. Government retains for itself, and others acting on its behalf, a paid-up, nonexclusive, irrevocable worldwide license in said article to reproduce, prepare derivative works, distribute copies to the public, and perform publicly and display publicly, by or on behalf of the Government. 


\section{DISCLAIMER}

This report was prepared as an account of work sponsored by an agency of the United States Government. Neither the United States Government nor any agency thereof, nor any of their employees, make any warranty, express or implied, or assumes any legal liability or responsibility for the accuracy, completeness, or usefulness of any information, apparatus, product, or process disclosed, or represents that its use would not infringe privately owned rights. Reference herein to any specific commercial product, process, or service by trade name, trademark, manufacturer, or otherwise does not necessarily constitute or imply its endorsement, recommendation, or favoring by the United States Government or any agency thereof. The views and opinions of authors expressed herein do not necessarily state or reflect those of the United States Government or any agency thereof. 


\section{DISCLAIMER}

Portions of this document may be illegible in electronic image products. Images are produced from the best available original document. 
beam into the linac line. One unique feature is the use of a fast crossed-field kicker to limit the current injected into the APS linac line [4] [5]. The new gun1 beamline was made to mirror the gun 2 beamline as closely as possible, including beamline component placement and if flange arrangement, allowing a possible future update to both guns with a single new gun design.

A sketch of the gun 1 and gun 2 injector beamline layout is shown in Figure 1.

\subsection{Power supply}

Two high-power if switches are used to provide power to the rf guns. The first switch in line determines whether the power from the first APS linac section exhaust is sent to a load or to the if guns. A second switch determines whether if power is directed towards gun1 or gun2. Since each switch has two input ports, the "spare" input port on the second switch is connected to a waveguide adapter, allowing a network analyzer to be used on whichever gun is not receiving high-power if.

\subsection{Required differences}

Because the gun1 alpha magnet is located so far from the linac, the gun1 alpha magnet must considerably overcompress the beam from gun1. The beam then ballistically recompresses during the drift to the linac. This requires a deep-orbit alpha magnet, with a maximum penetration depth of approximately $21 \mathrm{~cm}$. (This is in contrast to the gun2 system, which requires a maximum penetration depth into its alpha magnet of only $10 \mathrm{~cm}$.)

For several reasons, a Panofsky-style alpha magnet was chosen for the gun 1 beamline, as opposed to a more conventional parabolic pole-face geometry alpha magnet. The Panofsky geometry allows generation of the large required "good field" region with relative ease. The Panofsky-style quads and alpha magnets operate using current sheets, so the actual magnet construction is rather simple; this allowed tight construction and installation schedules to be met. Finally, the Panofskystyle alpha magnet, even with its large good-field region, is actually rather compact, allowing it to readily fit into the beamline.

The crossed-field kicker design is the same for both beamlines; however, the pulsed power supply for the gun1 kicker is located outside the tunnel, in a shielded rack enclosure, rather than inside the tunnel as is the gun2 kicker supply. This was done not only to reduce the amount of equipment located in the tunnel (and thus less accessible for maintenance) but also to attempt to reduce the noise introduced onto the beam current monitors when the kicker fires.

\subsection{Diagnostics}

The gun1 diagnostics are similar to those used for gun2. A beam current transformer is located immediately downstream of the gun, allowing the total beam current pulse to be measured and integrated for current stabilization via feedback on the cathode heater. A Faraday cup, located on the straight-through trajectory, allows verification of kicker operation and beam transport efficiency. A second beam current transformer downstream of the alpha magnet allows verification of beam transport through the alpha magnet.

After the beam from gun1 has been injected into the APS linac, all of the standard APS linac diagnostics, including wall current monitors, beam position monitors, fluorescent screens, spectrometers, etc., are available as well.

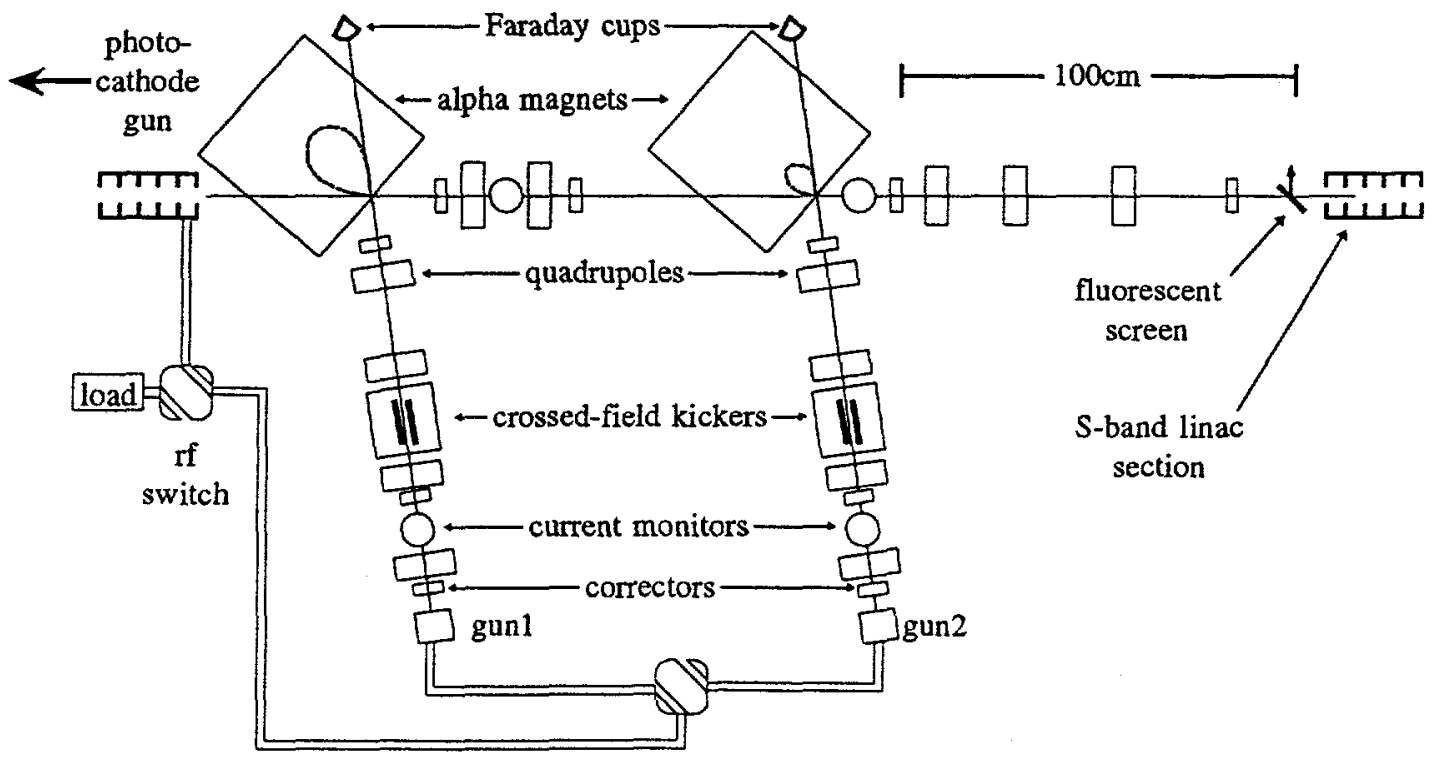

Figure 1: APS main injector layout. Trajectories in the alpha magnets are to scale. 


\section{PERFORMANCE TO DATE}

\subsection{Gunl testing}

Initial testing of gun 1 consisted of cathode beater cycling, low-power if measurements, and high-power if conditioning. Once installed in the tunnel and fully rf conditioned, gun1 was used to generate a 1-A (macropulse average) beam current without difficulty.

\subsection{Beamline components}

The gun1 alpha magnet was tested before installation and found to have acceptable field quality inside the region to be traversed by the electron beam; in fact, its field quality is better than gun2's more traditional parabolic pole-face alpha magnet. Larger than anticipated external (stray) fields were measured, especially when operating the magnet at higher currents. This" is due to the use of "back-leg"-style coils rather than saddle coils for the alpha magnet windings, a choice made in the interests of economy and fabrication time. The stray fields are not strong enough to overwhelm the available steering correction at the operating magnet currents, however.

The location of the crossed-field kicker supply outside of the linac tunnel has proved to be effective in reducing the noise introduced into the diagnostics signals.

\subsection{Operation as an APS injector}

Gun1 has successfully been operated as an injector for the APS, providing beam injection into the linac and through the APS injection system to the booster dump. Sufficient charge was delivered to allow a storage ring refill via gun1, should beam have been lost at that time.

Larger than anticipated beam current losses were encountered between gun 1 and its alpha magnet; this does not appear to be related to the alpha magnet stray fields, as the losses are also encountered when running beam to the gun 1 alpha magnet Faraday cup. Once through the alpha magnet, however, beam losses through to the end of the linac line and the remainder of the APS injection system were normal.

Commissioning of gun1 as an APS injector is continuing. As of this writing, the linac control software is being upgraded to automatically control either gun 1 or gun2 as the APS primary injector.

\section{POSSIBLE FUTURE UPGRADES}

Although the gun 1 injection system has been demonstrated to be operational, and control system integration is continuing, there are several possible future upgrades being considered.

\subsection{Alpha magnet coil upgrade}

As mentioned, the gun1 alpha magnet uses racetrackstyle coils rather than saddle coils. This is a less effi- cient design and is the most likely candidate for the cause of measured stray fields.

Pending additional commissioning studies and field measurements to determine requirements, a set of saddle coils for the gun1 alpha magnet could be complete and ready for installation during the December ' 99 - January '00 APS maintenance shutdown.

\subsection{Magnetic field probes for fast turnover}

Presently both gun1 and gun 2 alpha magnets are solidcore magnets, and if not degaussed, exhibit relatively strong residual fields. In order to achieve good beam transport from the gun1 alpha magnet to the linac entrance, a relatively long degauss cycle must be completed on the gun2 alpha magnet. Both alpha magnets should be thoroughly degaussed when running the photocathode gun in order to help preserve beam emittance.

By including a magnetic field sensor such as a Hall probe inside both alpha magnets, the APS control system could be used to automatically adjust the alpha magnet trim supplies to zero the field completely without the need for a long degauss cycle. This would assist both in experimental operation of the photocathode gun and in the use of gun1 as a hot-spare injector, as presently the gun2 alpha magnet degauss is the longest task in the switchover process.

\subsection{Diagnostics}

Although beamline space in the main injector area is now limited, there is still room for additional diagnostics. In particular, a longitudinally thin wire scanner placed at the entrance of both alpha magnets would considerably aid in obtaining proper injection into the alpha magnets. Also, a beam position monitor could be placed immediately before the linac entrance aperture. This would allow automatic beam transport and steering optimization between either alpha magnet and the linac entrance.

\section{ACKNOWLEDGEMENTS}

We would like to thank Charles Doose, George Goeppner, John Noonan, Stan Pasky, and Dean Walters for their assistance and support of the fabrication, installation, and commissioning of the gun 1 injector system.

\section{REFERENCES}

[1] L. Emery and M. Borland, "Top-Up Operation Experience at APS," these proceedings

[2] S.V. Milton et al., "Status of the Advanced Photon Source LowEnergy Undulator Test Line," FEL '97, Beijing, (1997)

[3] M. Borland, et al., "Performance of the $2 \mathrm{MeV}$ Microwave Gun for the SSRL $150 \mathrm{MeV}$ Linac," LINAC '90, Albuquerque, (1990)

[4] J.W. Lewellen et al., "Operation of the APS RF Gun," LINAC '98, Chicago, (1998)

[5] Y.W. Kang et al., "Beam Chopper for the Low-Energy Undulator Test Line (LEUTL) in the APS," PAC '97, Vancouver, (1997) 